\title{
Bilateral attachment of corneal endothelium to lens implants in corneal collapse at death: a pseudophakic eye with a Fuchs' epithelioma *
}

\author{
J. Reimer Wolter \\ Departments of Ophthalmology and Pathology, University of Michigan Hospitals, Ann Arbor, MI 48109, USA
}

\begin{abstract}
The pathological situation of bilateral attachment of corneal endothelium to iris plane lens implants, due to collapse of the anterior chambers, is recorded in a patient who died of heart failure. The additional observation of a Fuchs' epithelioma on the ciliary body adjacent to the implant in one of the eyes is used to start a discussion about possible interactions between lens implants and unsuspected intraocular tumors.
\end{abstract}

\section{Introduction}

Observation and detailed recording of the pathology of all the possible reactions and associated histological and cytological changes are essential for progress in the clinical understanding and the further improvement of intraocular lens implantation. Every opportunity for the collection of pathological details should be used to give more insight into the world of lens implant cytology and pathology. It is believed that a feeling for the pathology in a new clinical field can be gained by simple reporting and gradual accumulation of such details.

The unusual and somewhat complex observations on the two eyes obtained after death of a patient with two different types of lens implants are thus presented. The aim is to record pathological facts and to develop an understanding of the spectrum of the reactive and other complicating processes which may take place in pseudophakic eyes.

\section{Case report}

An 84-year-old Caucasian female was first seen by a New Jersey ophthalmologist on 5 March 1975 with a history of progressive visual loss in both eyes. Examination revealed best corrected visual acuity of 20/200 in the right eye and counting fingers at 10 feet in the left. Moderately dense nucleosclerotic cataracts partly explained the reduction in visual acuity, but degenerative changes of the central retina were also recognized in both eyes. The options were discussed and the patient decided to have a cataract extraction in the left eye with an intraocular lens implantation.

Intracapsular cataract extraction with insertion of a Co-

* Supported by the Research to Prevent Blindness, Inc., New York, N.Y., USA peland intraocular lens implant was carried out in the left eye without complications on 9 June 1975. Senile macular degeneration with temporal pallor of the optic disk became clearly visible. However, vision in the eye which had been operated upon improved to 20/200 and the patient was satisfied.

A decrease in the vision of the right eye to $20 / 400$ led to cataract surgery which was performed by the same New Jersey ophthalmologist on 3 January 1978. Again, intracapsular lens extraction was attempted, but the capsule ruptured and the posterior capsule was left in the eye. A fourloop Binkhorst implant was inserted with a transiridectomy suture. Vision in the right eye improved to $20 / 100+2$. The right eye also had distinct senile macular degeneration. On 11 December 1979 an additional discission of a secondary membrane became necessary in the right eye.

At her last examination on 17 September 1981 the patient had a vision of 20/200 in both eyes, and this was explained by the presence of senile macular degeneration. There were no clinical signs of iritis, but on slit lamp examination the right lens implant exhibited a few precipitates on its surface. The patient died on 12 April 1983 of congestive heart failure and coronary insufficiency. When the surgeon who performed the catarract surgery obtained her eyes $12 \mathrm{~h}$ after death, he observed, prior to enucleation, that the anterior chambers were grossly collapsed in both eyes. The patient did not exhibit signs of obvious general dehydration. The eyes were fixed in 10\% formalin immediately after their removal.

\section{Pathological description}

The eyes were of normal size, but the anterior chambers had collapsed and the corneas were inverted. This had resulted in grossly visible touch of the center of the posterior surface of the cornea to the center of the front surface of the intraocular lens implants in both eyes.

The left eye contained a Copeland lens implant at the desired position in the iris plane. The anterior vitreous face in the left eye was preserved and remained intact when the lens implant was removed.

The left eye exhibited posterior vitreous detachment and vitreous retraction. The Copeland lens implanted more than 7 years before was studied with the lens implant cytology technique [3]. It was found to be continuously covered with a filmlike porteinaceous capsule populated by rather regularly distributed fibroblastlike cells (Figs. 1 and 2). Occa- 


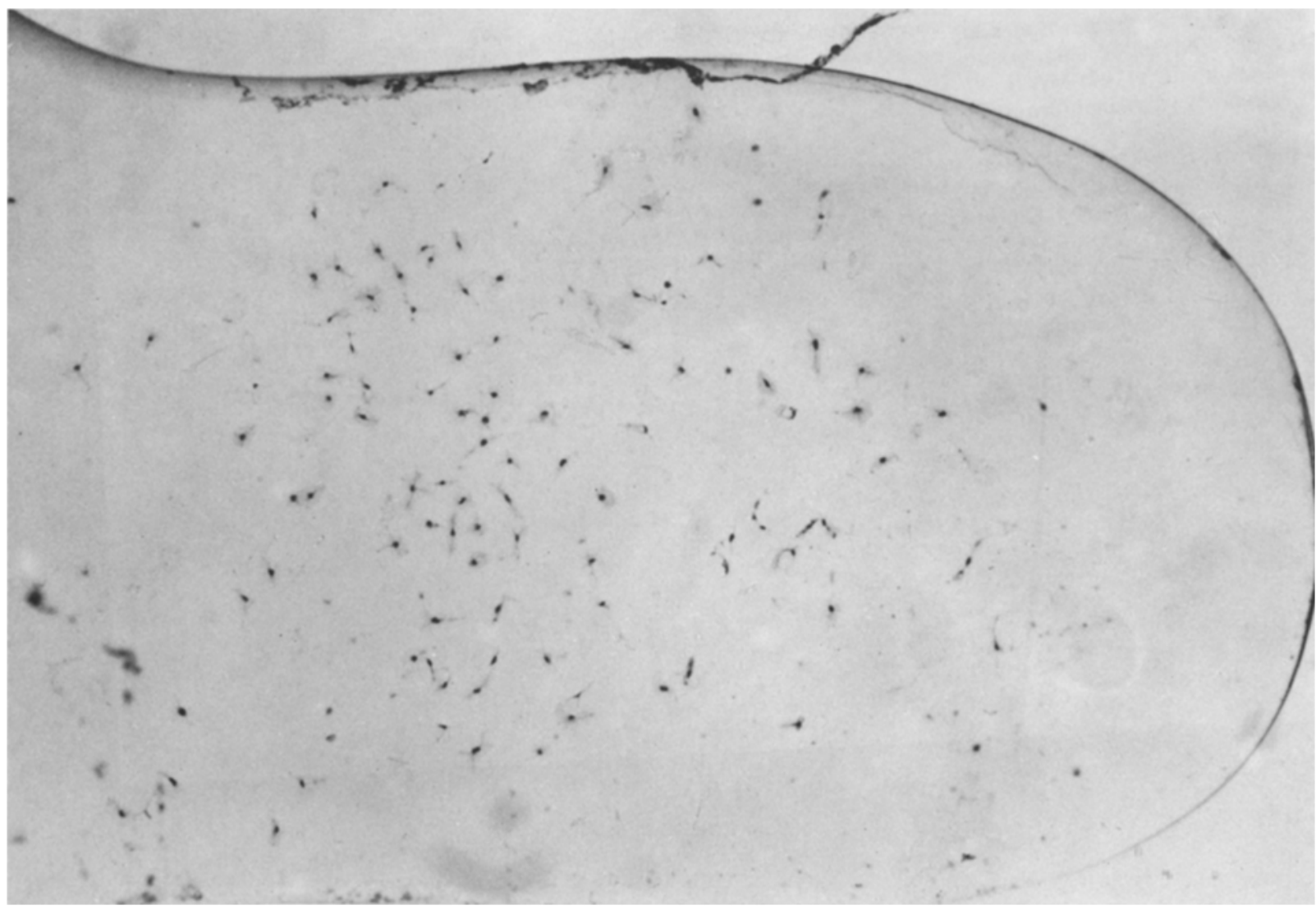

Fig. 1. Haptic portion of Copeland lens implant covered by a continuous eosinophilic capsule with numerous fibroblastlike cells. Lens implant cytology technique, $\mathrm{H} \& \mathrm{E}$ stain, photomicrograph $\times 50$

sional large cells with long processes (Fig. 3) were also found in this membrane, but there were no giant cells or other signs of active granulomatous inflammatory or foreign body reaction. The center of the front surface of the reactive membrane on the Copeland lens exhibited an island of firmly attached corneal endothelium (Fig. 4). This island was composed of about 50 adjacent cells with preserved intercellular membranes. Some of these endothelial cells contained very well preserved nuclei, while the nuclei were missing in other cells (Fig. 5). The endothelial cells without a nucleus exhibited a round hole in the place of the nucleus.

Paraffin sections of the left eye cut in a vertical plane revealed a continuous epithelium. Bowman's membrane was very well preserved centrally, but it was absent and replaced by scar tissue in an area next to the old cataract incision at the superior limbus. Descemet's membrane was preserved and of normal thickness. Portions of the corneal endothelium were missing and the preserved endothelium exhibited some diffuse loss of cells. The anterior chamber angle was open. The filtering trabeculum was preserved, but it contained much pigment. Iris and ciliary body contained some mononuclear inflammatory cells mainly in the zone of the iris root. There were areas of atrophy of both, the iris stroma and the pigment epithelium. The vitreous face was intact and no lens remnants were found. The peripheral retina exhibited cystoid degeneration and advanced atrophy and scarring associated with atrophy of the pigment epithelium. Extensive degeneration and scarring with drusen were seen in the central retina.
The right eye revealed the Binkhorst four-loop implant placed 5 years before death. This was also covered by a continuous reactive membrane with fibroblastlike cells. Again, there were no giant cells or other signs of a granulomatous reaction. However, another even larger patch of corneal endothelium was found attached to the front surface of this lens implant next to the insertion of one of its front haptics (Fig. 6). The situation was very similar to that of the left eye - with preservation of the endothelial cell limits and holes in the place of some of the cellular nuclei.

Paraffin sections of the right eye cut in a vertical direction confirmed the grossly observed collapse of the cornea (Fig. 7). Some separation of the corneal epithelium from Bowman's membrane resembled that seen in bullous keratopathy. The chamber angle was open. Iris and ciliary body exhibited slight and diffuse mononuclear infiltration. A large peripheral iridectomy was seen (Fig. 7). A partial Soemmering's ring with large Wedl cells was found inferiorly. A Fuchs' epithelioma was in direct contact with the Soemmering's ring (Figs. 7 and 8). The Fuchs' epithelioma appeared histologically inactive and no signs of irritation or bleeding were seen in or adjacent to it. Parts of the posterior lens capsule were seen in the pupil (Fig. 9). The vitreous face in the right eye was preserved, and there was posterior vitreous detachment with retraction. The changes in retina and pigment epithelium were very similar to those seen in the left eye, and a diagnosis of associated central retinal degeneration could be made. 


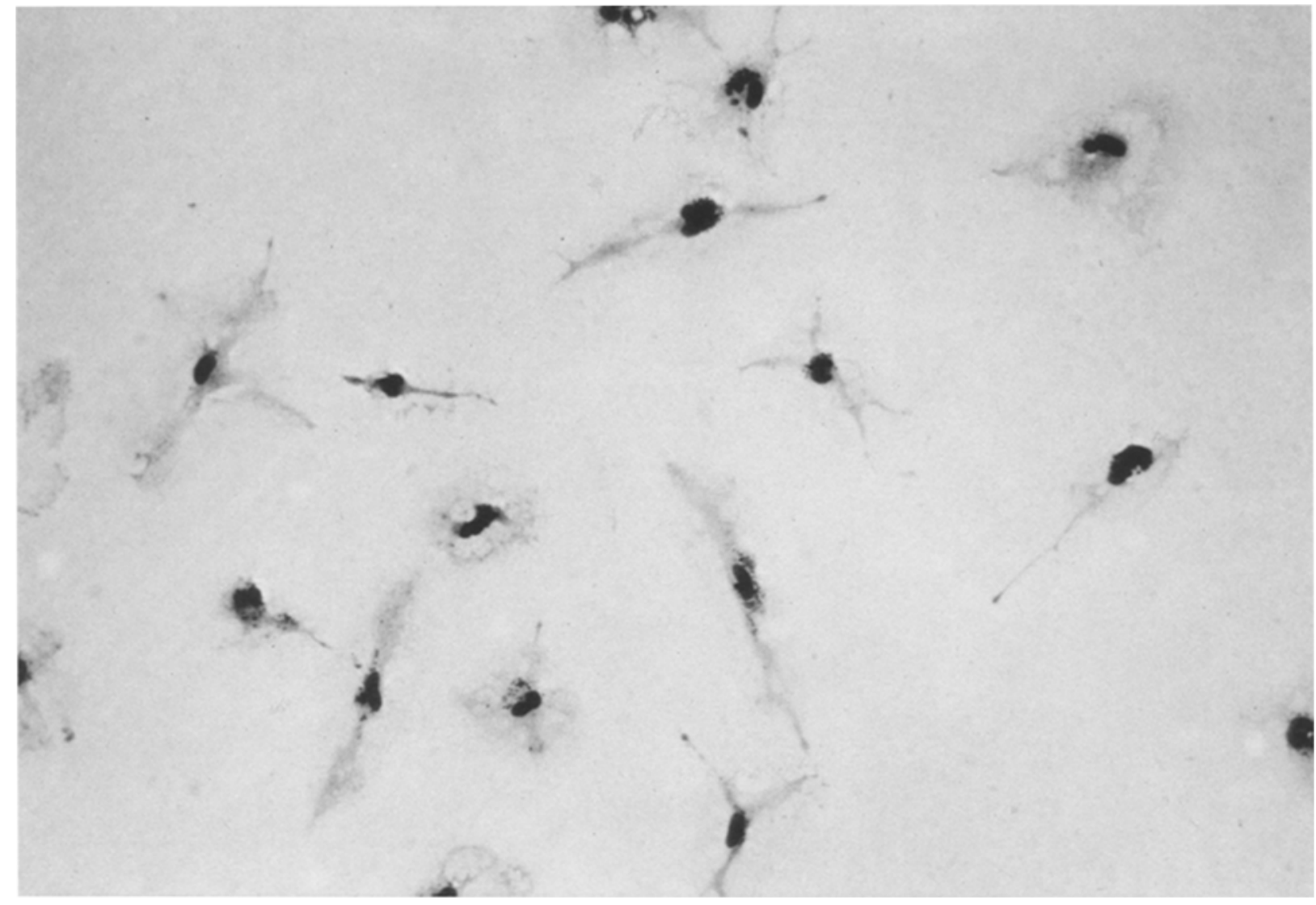

Fig. 2. High-power view of the typical fibroblastlike cells on the optic portion of the Copeland lens implant. Lens implant cytology technique, H \& E stain, photomicrograph $\times 300$

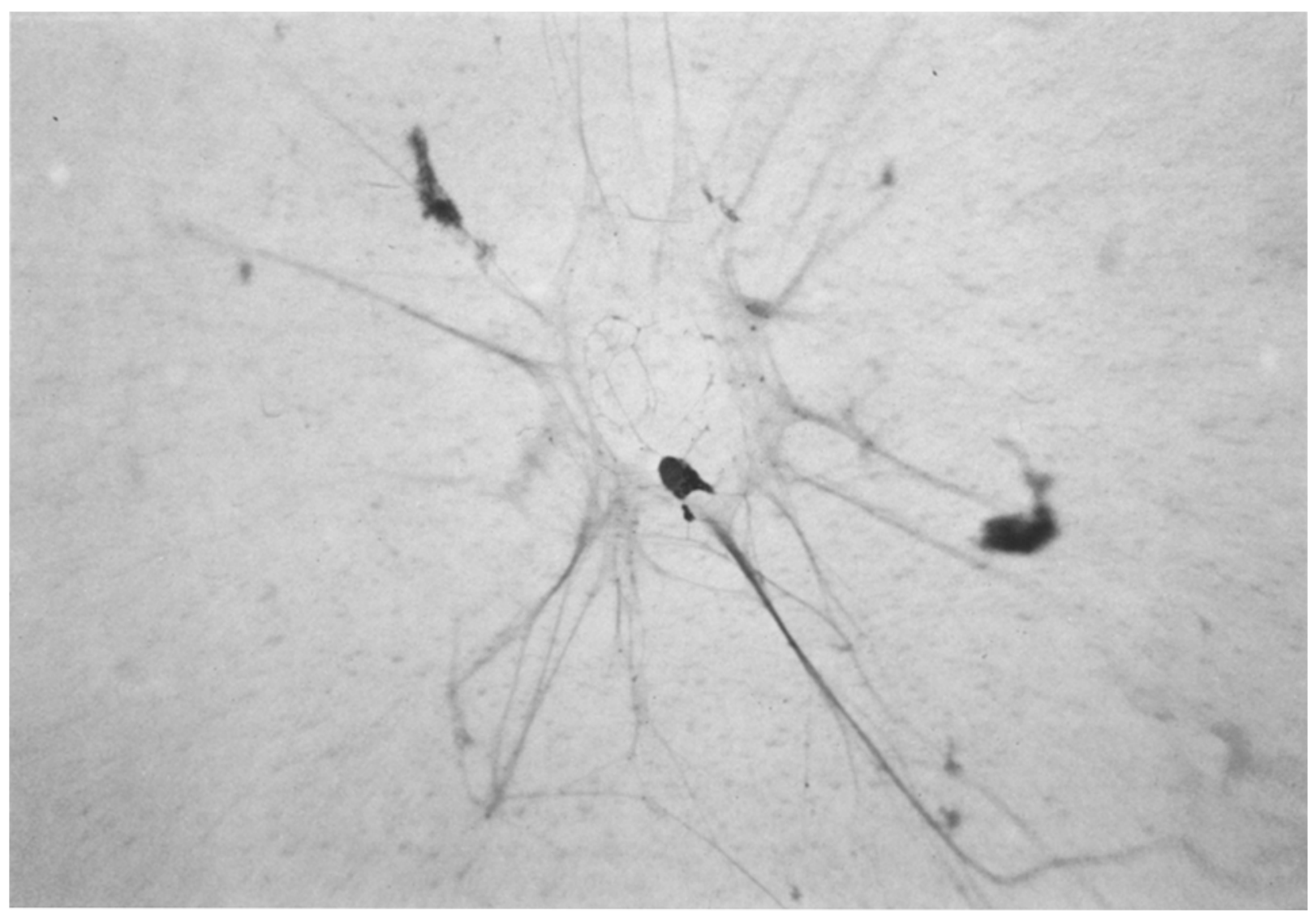

Fig. 3. One unusually large mononuclear fibroblastlike cell on the surface of the Copeland lens implant with many starlike processes. Lens implant cytology technique, H \& E stain, photomicrograph $\times 300$ 


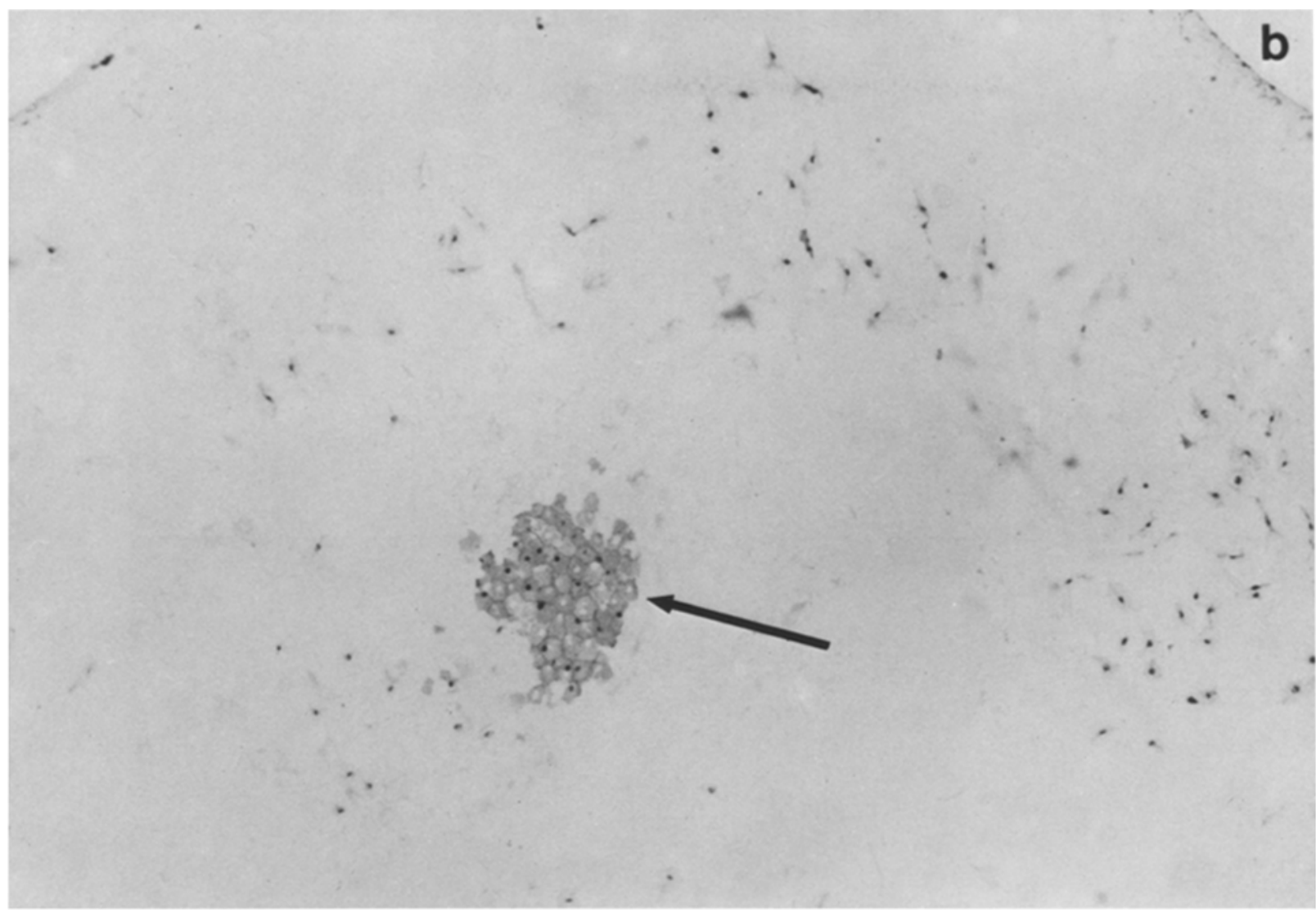

Fig. 4. Front surface of the optic portion of the Copeland lens with numerous fibroblastlike cells and one island of about 50 continuous corneal endothelial cells (arrow). The border of the central part of the cross-shaped implant is seen on the upper right $(b)$. Lens implant cytology technique, $\mathrm{H} \& \mathrm{E}$ stain, photomicrograph $\times 50$

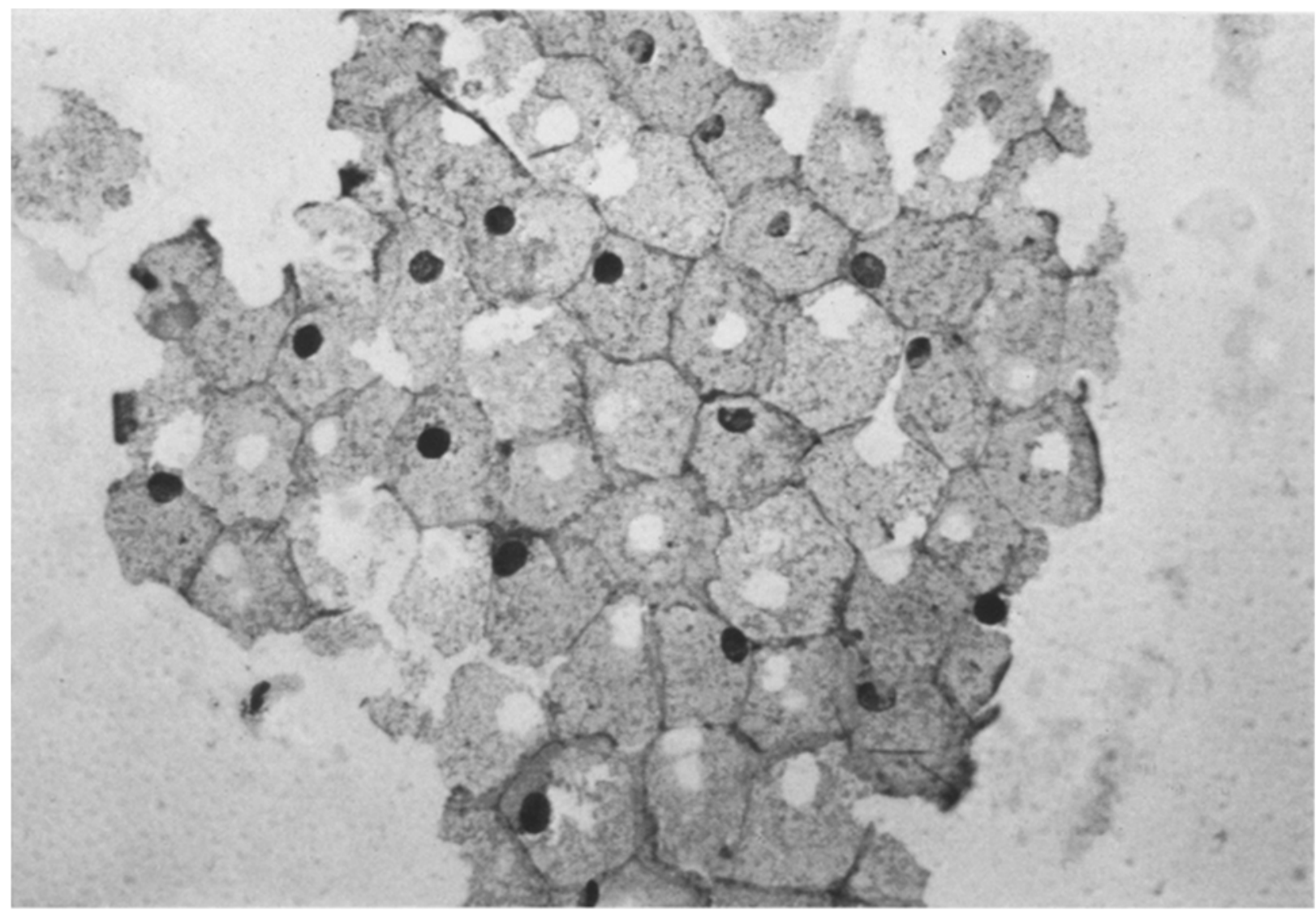

Fig. 5. High-power view of the patch of corneal endothelium attached to the front surface of the Copeland lens implant. Some cells have their nuclei, whereas others exhibit a hole in the place of the nuclei. Lens implant cytology technique, $\mathrm{H} \& \mathrm{E}$ stain, photomicrograph $\times 300$ 


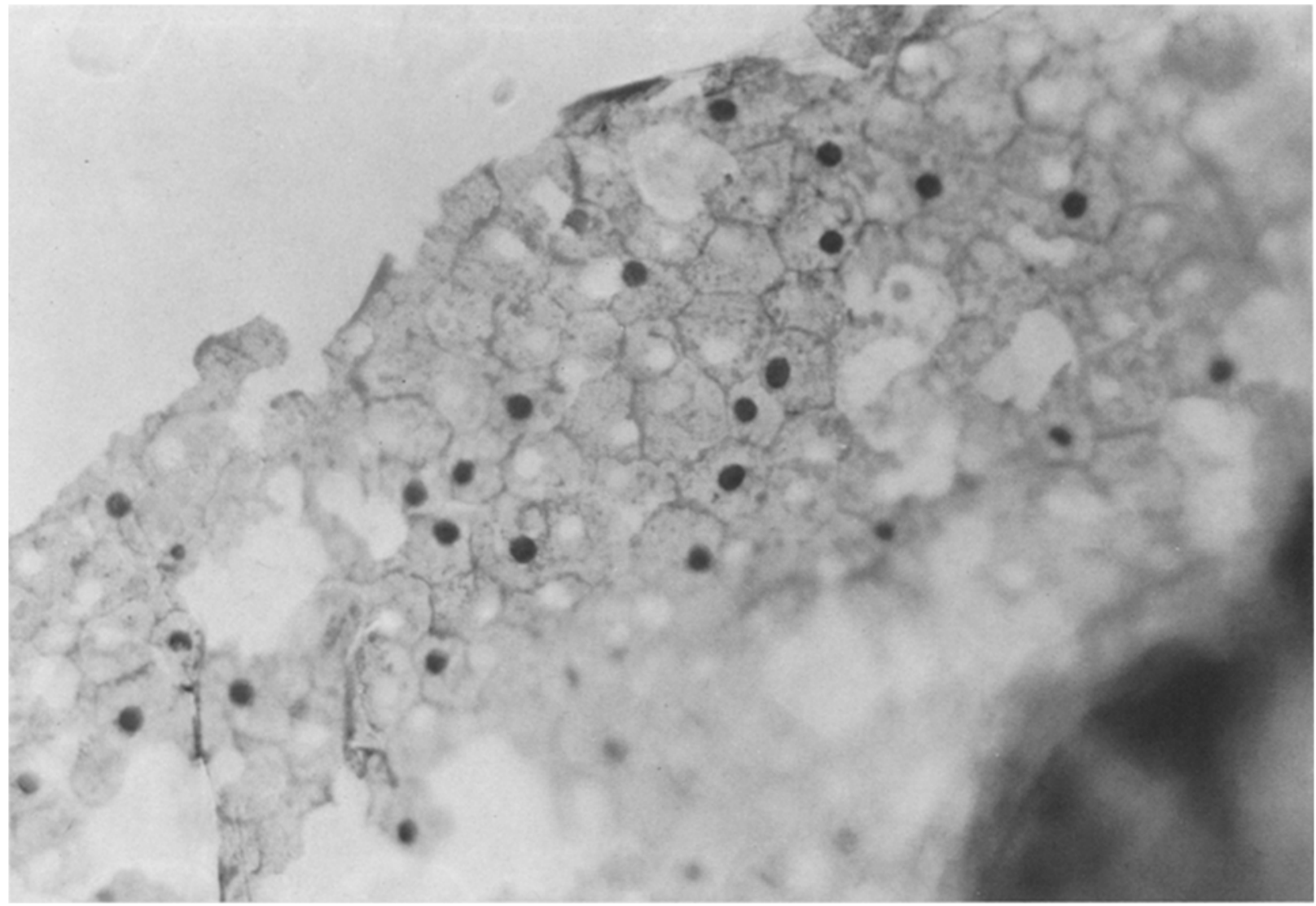

Fig. 6. Continuous corneal endothelium attached to the anterior surface of the optic portion of the Binkhorst lens implant. The insertion of one of the front haptics is seen on the lower right. Lens implant cytology technique, $\mathrm{H} \& \mathrm{E}$ stain, photomicrograph $\times 300$

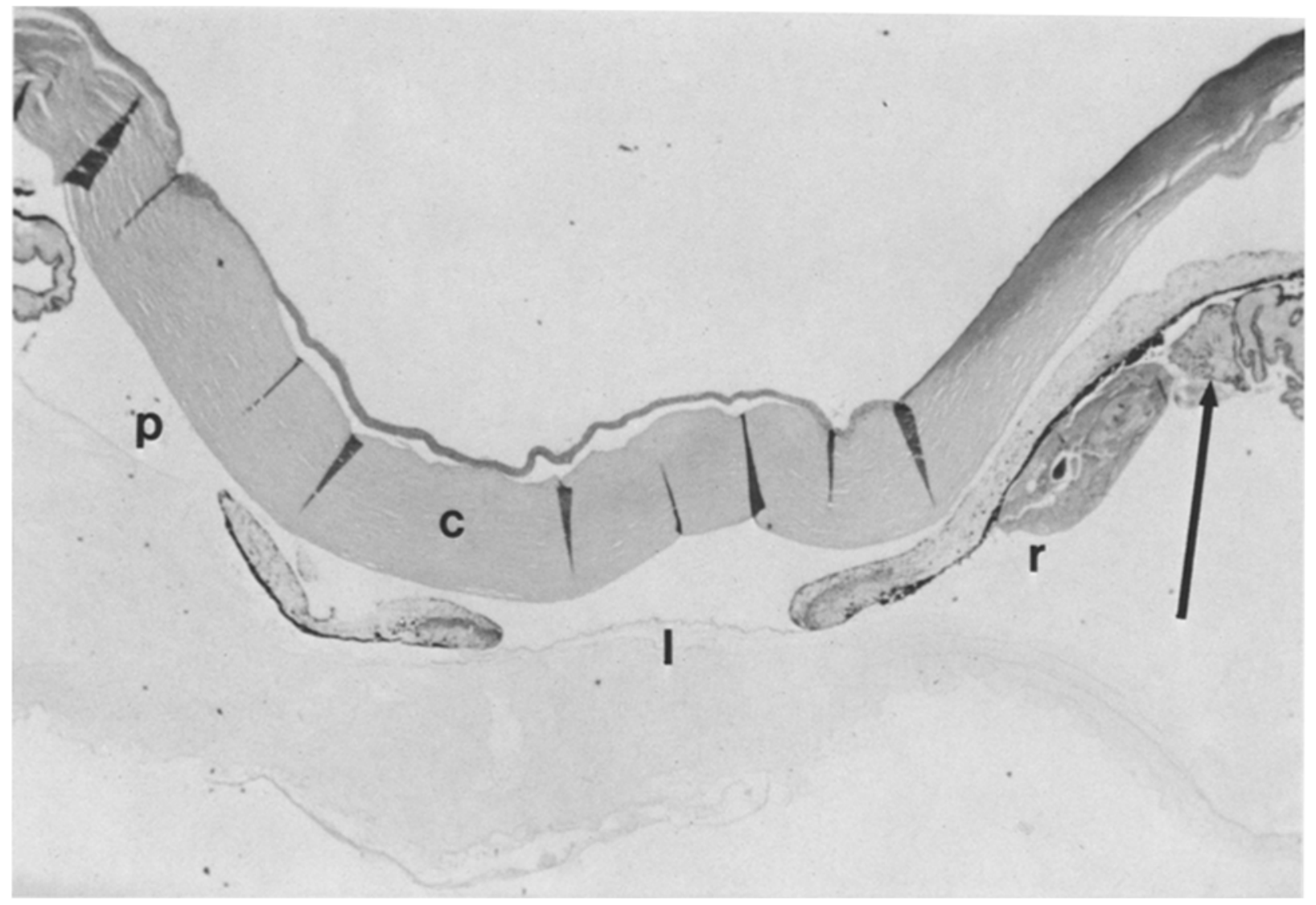

Fig. 7. Vertical section through the anterior segment of the right eye with the collapsed cornea (c), the peripheral iridectomy ( $p$ ), the preserved posterior lens capsule in the pupil $(l)$, the partial Soemmering's ring $(r)$, and the Fuchs' epithelioma (arrow). Paraffin section, $\mathrm{H} \& \mathrm{E}$ stain, photomicrograph $\times 15$ 


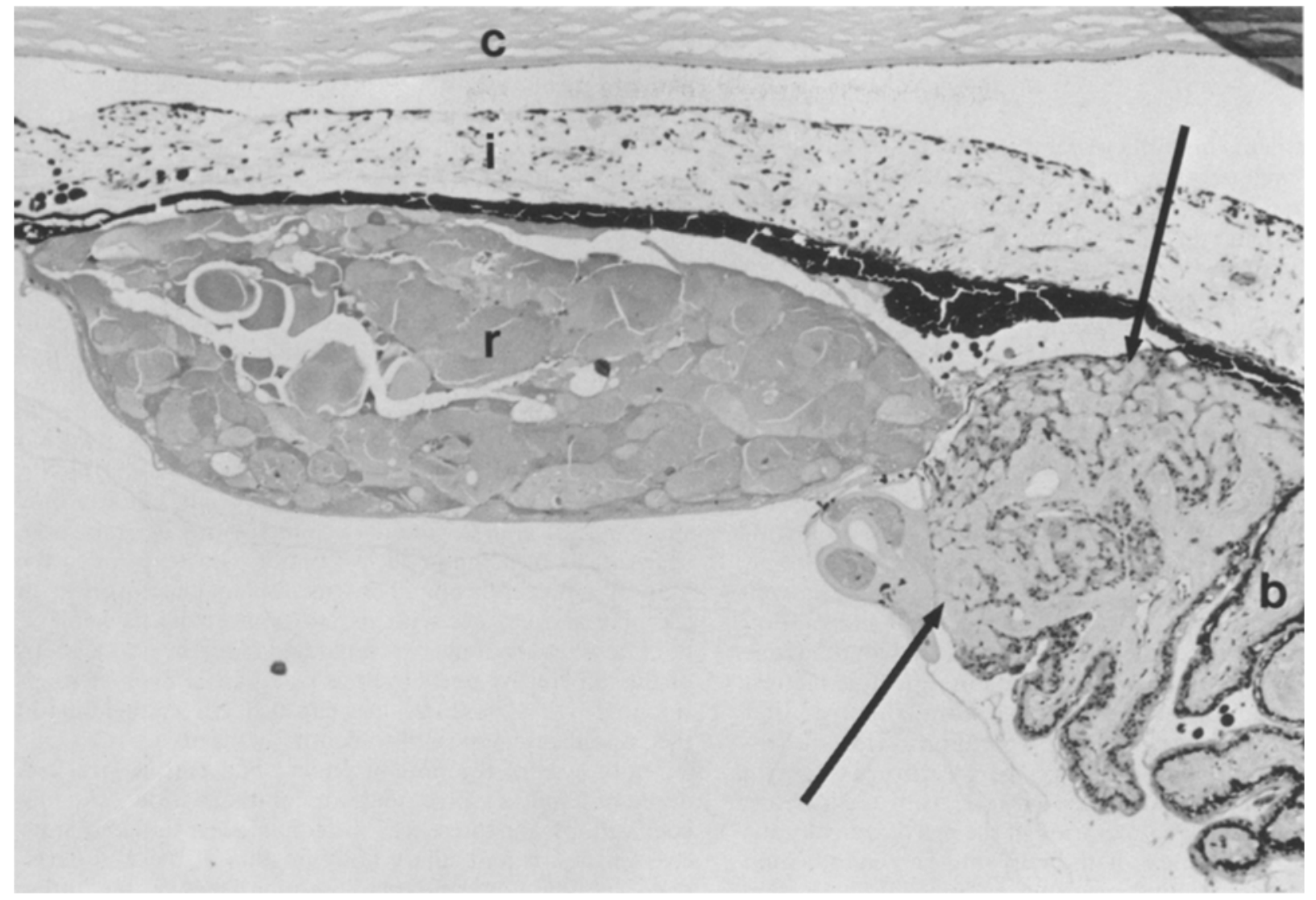

Fig. 8. Fuchs' epithelioma (arrow) on the ciliary body $(b)$ with directly adjacent Soemmering's ring $(r)$ and peripheral iris $(i)$. The posterior surface of the collapsed cornea $(c)$ is seen above. Paraffin section, H \& E stain, photomicrograph $\times 80$

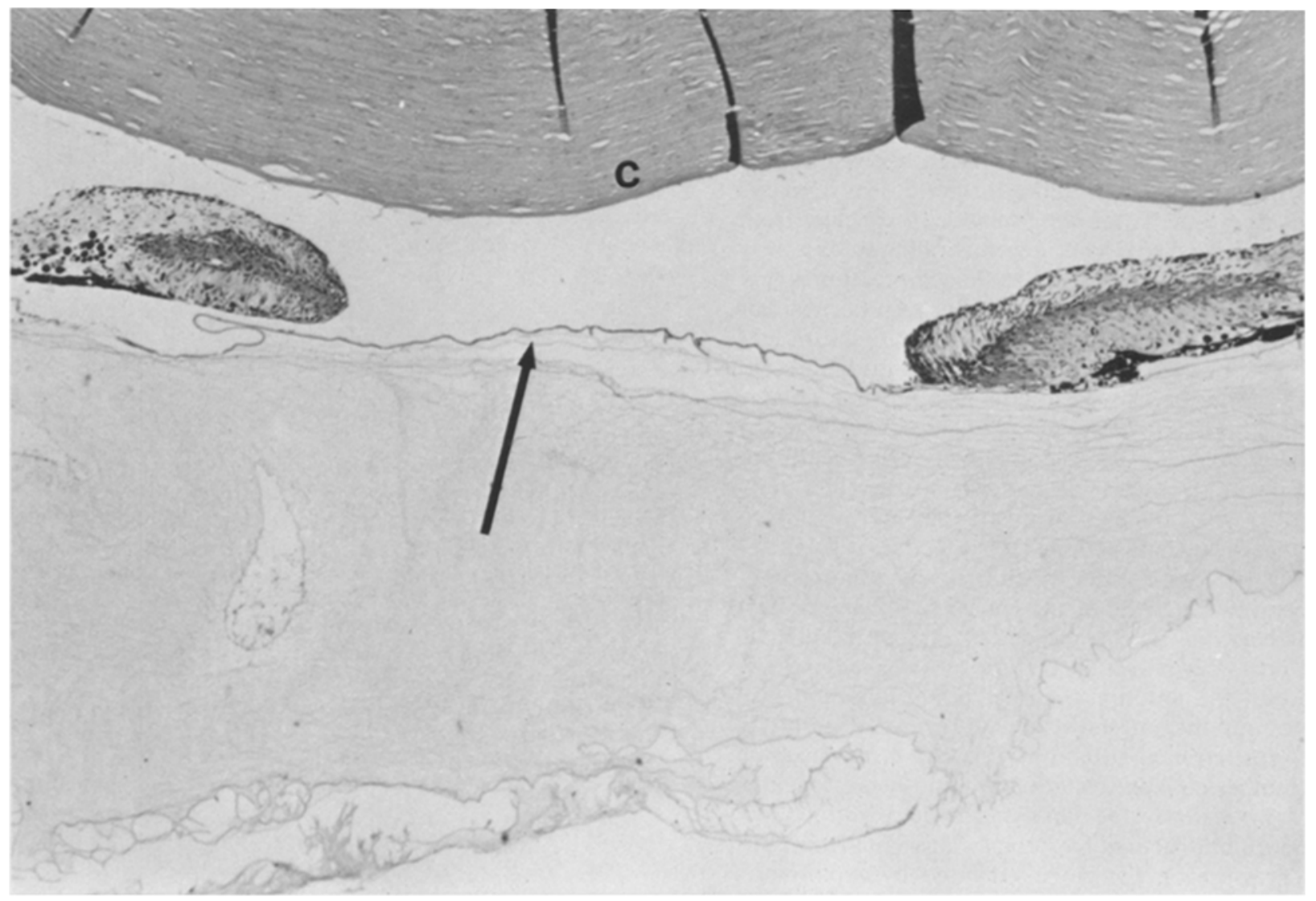

Fig. 9. Continuous posterior lens capsule (arrow) in the pupil of the right eye. The posterior surface of the collapsed cornea (c) is seen above. Paraffin section, H \& E stain, photomicrograph $\times 80$ 


\section{Discussion}

The lens implants in both eyes of this patient were encapsulated by a well-developed and continuous, reactive membrane composed of inactive fibroblastlike cells with a filmlike proteinaceous layer covering the interspaces between the cells. Experience has taught that this type of a reactive membrane is typically seen in successful lens implants [4, 5]. Collapse of the anterior chambers had resulted in central contact of the corneal endothelium and the anterior surface of the lens implants in both eyes. The reason for the collapse of both anterior chambers of this patient is not clear, but this is believed to be associated with a terminal failure of blood pressure, blood circulation, and intraocular pressure in combination with general dehydration. It is well known to all eye surgeons that some eyes tend to respond to hypotony with scleral collapse, whereas other eyes have a rigid sclera and first exhibit corneal collapse. Both eyes were fixed in formalin in this position of corneal indentation and touch between corneal endothelium and the reactive membranes on the implants. It is of the greatest interest that the removal of the lens implants from both eyes after completed fixation resulted in a separation of this attachment within the endothelial layer of the cornea - not in a separation of the endothelial surface from the reactive membrane and not in a separation of the reactive membrane from the plastic surface of the implant. The endothelium was ripped apart - with some of the endothelial nuclei staying on the corneal surface and others on the lens implant. This gives an indication of the remarkable strength of the attachment of the reactive membrane to both lens implants after fixation.

It is impossible to say at this point how much of this firm connection between corneal endothelium and reactive membrane on the lens implants had already developed as a result of the touch between the living cells and how much of this is due to fixation. However, I have observed attachment of corneal endothelium to the surface of lens implants in instances where the latter were removed surgically from living eyes (unpublished). The present finding adds a new dimension to this earlier observation. The impression is that a great affinity exists in the living eye between corneal endothelium and the elements of reactive membranes on lens implants. I am sure the corneal collapse seen in the present case would simply be classified as a post-mortem change by most clinicians. However, the changes taking place in an eye shortly before, during, and shortly after death are gradual and transitional. The endothelial cells certainly were still alive when the eyes of this patient were removed $12 \mathrm{~h}$ after her heart had stopped beating. Inactive fibroblastlike cells on lens implants would be expected to continue living even longer than the endothelial cells. A firm attachment between the membranes of these cells, thus, is of great interest - even if it occurred after clinical death.

Collapse of the anterior chamber is not common in a healthy eye, but the present case shows that it certainly can occur in a terminal situation. One can easily imagine anterior chamber collapse resulting in endothelial touch to an implant in a survivable illness with dehydration, low blood pressure and ocular hypotony. This could be reinforced by pressure on the globe - caused by a pillow or rubbing fingers, for example. In view of the present findings and the suspected affinity of the corneal endothelium to the reactive membranes on lens implants, this kind of touch is not safe in pseudophakic eyes.

The unsuspected presence of a Fuchs' epithelioma in one eye of the present case is another matter of great interest for the lens implant surgeon. Fuchs' epitheliomas are also known as benign ciliary epitheliomas. They commonly occur on the ciliary body in front of the equator of the lens and frequently are directly adjacent to, or even continuous with, the peripheral iris [7]. Fuchs' epitheliomas have been found in $14 \%$ to $18 \%$ of eyes at autopsy [1, 2]. Fuchs' epitheliomas usually are a clinically unimportant accidental finding in the eyes of old people. However, a basic relationship to the actively growing medulloepitheliomas of the ciliary epithelium is suspected [6]. At this point, one can only speculate, of course, about the possibilities of activation, necrosis, or bleeding in such a tumor as a reaction to the loop of a posterior chamber lens implant placed on it. In the present right eye with its iris-supported lens implant, the Fuchs' epithelioma was separated from the haptic loops of the implant by the substance of a partial Soemmering's ring and by the posterior lens capsule. The epithelioma in the present case appeared to be totally inactive.

Both eyes of the present patient had pathological evidence of a mild chronic nongranulomatous iridocyclitis recognized by the presence of mononuclear inflammatory cells in the iris and ciliary body in spite of the well developed, continuous, and cytologically inactive separating membranes on the surfaces of the lens implants. Indications are that this chronic iridocyclitis had not caused serious damage to the corneal endothelium. The central retina and pigment epithelium already had advanced atrophy and scarring as part of the primary central retinal degeneration, before the lens implantations were inserted. The full value of the details observed in the post-mortem study of these two eyes will become clear only after the study of many more eyes of this type which will enable proper perspective.

Acknowledgement. This is to thank S. Jerome Holtz, M.D., of Bloomfield, New Jersey, for obtaining and sending the eyes used for this pathological study.

\section{References}

1. Bateman JB, Foos RY (1979) Coronal adenoma. Arch Ophthalmol 97:2379-2384

2. Iliff WJ, Green WR (1972) The incidence and histology of Fuchs' adenoma. Arch Ophthalmol 88:249-254

3. Wolter JR (1982) Lens implant cytology. Ophthalmic Surg 13:939-942

4. Wolter JR (1982) Cell life on the surface of lens implants. Graefe's Arch Clin Exp Ophthalmol 218:244-249

5. Wolter JR (1983) Morphology of the capsulelike portion of the reactive membranes on intraocular lens implants. Graefe's Arch Clin Exp Ophthalmol 220:58-65

6. Wolter JR, Pfister RR (1961) Tumors of the pars ciliaris retinae. Am J Ophthalmol 52:659-672

7. Zaidman GW, Johnson BL, Salamon SM, Mondino BJ (1983) Fuchs' adenoma affecting the peripheral iris. Arch Ophthalmol $101: 771-773$

Received September 21, 1983 